\title{
Helicobacter pylori rate and histopathological evaluation in HBeAg-negative chronic hepatitis B virus infection
}

\author{
Osman Özdoğan, Serkan Yaras
}

Department of Gastroenterology, Mersin University, Mersin, Turkey

Submitted: 24 August 2019

Accepted: 9 September 2019

Arch Med Sci Civil Dis 2019; 4: e97-e103

DOI: https://doi.org/10.5114/amscd.2019.91449

Copyright @ 2019 Termedia \& Banach

\begin{abstract}
Introduction: Studies of Helicobacter pylori (HP) in liver diseases and hepatitis $B$ virus (HBV) infection have been increasingly discussed. Most studies investigating the relationship between HP and HBV have been conducted in patients with cirrhosis and hepatocellular carcinoma (HCC) and usually involving noninvasive tests. The HP frequency in these patients was higher than in healthy controls. No histopathological evaluation was performed in these studies. We investigated the incidence of HP in HBeAg-negative chronic HBV infection (previously termed "inactive carrier") by using invasive gastric biopsies and carried out histopathological evaluation.

Material and methods: We included 90 treatment-naive inactive hepatitis-B carriers as patients. The control group comprised 107 healthy subjects. $\mathrm{Bi}-$ opsies were obtained from the antrum and corpus and were evaluated histopathologically using the Sydney system of classification for gastritis.

Results: The rate of HP in inactive hepatitis-B carriers was significantly higher than the control group $(75.6 \%$ vs. $53.3 \%$, respectively; $p=0.001)$. There was no difference in incidence of atrophy, intestinal metaplasia, activity, or inflammation $(p>0.05)$. Peptic ulcer was detected in $11(12.2 \%)$ patients in the HBV group and in $7(6.5 \%)$ patients in the control group $(p=0.360)$. The incidence of HP was higher in patients with HBV DNA $\geq 2000 \mathrm{IU} / \mathrm{ml}$ than in patients with HBV DNA $<2000 \mathrm{IU} / \mathrm{ml}$, but this difference was not statistically significant ( $85 \%$ vs. $68 \%$, respectively; $p=0.062$ ).

Conclusions: Although the HP rate in inactive hepatitis-B carriers was higher than the control group, there were no intergroup differences with respect to atrophy, intestinal metaplasia, activity, inflammation, and peptic ulcer frequency.
\end{abstract}

Key words: Helicobacter pylori, hepatitis B, endoscopy.

\section{Introduction}

Helicobacter pylori (HP) is a gram-negative, microaerophilic, spiral, gastric-resistant bacteria that resides in the mucus lining covering the gastric epithelial cells. The microorganism mainly colonizes in the antrum (prepyloric area) [1]. It is also associated with chronic gastritis, peptic ulcer disease, and gastric cancer. It is a commonly occurring pathogen worldwide, especially in developing countries, and more than $50 \%$ of the world's population carry HP in their gastrointestinal tracts [2]. HP may cause local and general proinflammatory cytokines to be released, resulting in extragastric organ disturbance leading to hematological dis-

\author{
Corresponding author: \\ Assist. Prof. Osman Özdoğan \\ Department \\ of Gastroenterology \\ Mersin University \\ Mersin, Turkey \\ E-mail: smnzdgn@yahoo.com
}


eases, cardiovascular diseases, and especially liver diseases $[3,4]$. Some studies have shown that H. pylori infection has a detrimental effect on the progression of liver damage, especially fibrosis $[5,6]$. Invasive and noninvasive methods are used for HP detection. One of the gold standard diagnostic methods in HP screening is endoscopic biopsy followed by histopathological examination [7].

In a study, 248 million people worldwide were estimated to be carriers of chronic HBV surface antigen (HBsAg) in 2010 [8]. More than half of these patients have $\mathrm{HBe}$ antigen negative chronic HBV infection (previously termed "inactive carriers") and these patients are usually followed up without treatment. Over time, some of these patients may develop active disease that progresses to cirrhosis and hepatocellular carcinoma (HCC) [9].

In previous studies, HP prevalence was found to be high in patients with HBV- or hepatitis $C$ virus (HCV)-related cirrhosis and HCC, and it was emphasized that HP could contribute to disease progression $[10,11]$. However, the role of HP in the pathogenesis of HBV-related diseases is still unclear [12]. In most studies investigating the relationship of HP in inactive hepatitis B carriers, noninvasive methods of HP diagnosis are typically used, with no histopathological evaluation [12-15]. Herein, we evaluated the HP frequency in inactive HBV carriers using gastric biopsy and investigated the histopathological differences. We also investigated whether there were differences in the group with high HBV DNA (cut-off: $2000 \mathrm{IU} / \mathrm{ml}$ ).

\section{Material and methods}

\section{Patient collection}

Ninety patients with HBV (patient group) and 107 healthy subjects (control group) were included in the study. The patient group consisted of those who applied to our clinic between March 2016 and December 2018. The patients with HBV were $\mathrm{HBe}-\mathrm{Ag}$ negative, treatment-naïve, non-cirrhotic patients who had normal transaminase levels (at least three times in the past year). All patients and controls had dyspeptic symptoms and were older than 18 years. The following exclusion criteria were applicable to both study groups: receipt of antibiotics for HP within the past 1 year; receipt of proton pump inhibitors (PPIs), antibiotics, and non-steroidal anti-inflammatory drug (NSAID) treatment in the last one month; history of gastric surgery or gastrointestinal bleeding; alcohol consumption; any chronic illness; and cirrhotic findings in abdominal ultrasonography. This study was approved by the local ethics committee of our hospital. The research has been in accordance with the Declaration of Helsinki. Written and verbal informed consent was obtained from all patients before the start of the study.

\section{Endoscopy}

Endoscopic evaluation was performed after about $10 \mathrm{~h}$ of fasting. A flexible gastroscope (Fujinon or Pentax gastroscope) was used. The esophagus, stomach, duodenal bulb, and the second part of the duodenum were evaluated. At least four biopsies (two each from the antrum and corpus) were taken from all patients in the antrum (especially from the prepyloric area) and the corpus (large and small curvature) regions. Esophagitis, ulcers, gastritis, and duodenitis were defined as endoscopic findings.

\section{Histology}

The biopsy samples were quickly transferred to formaldehyde solutions and sent to the pathology laboratory. Tissues were routinely processed, embedded in paraffin and cut into 5-6 $\mu \mathrm{m}$-thick sections. All sections were stained with PAS Alcian blue (for intestinal metaplasia (IM)) and modified Giemsa (for HP). Histopathological evaluation was made according to the updated Sydney classification [16]. Inflammation, HP, activity, atrophy, and $\mathrm{IM}$ were interpreted by a pathologist in a doubleblind manner.

\section{Serological, biochemical, and HBV DNA assay}

Blood samples were collected after a minimum fasting period of $8 \mathrm{~h}$. Complete blood count, biochemical, and other tests were conducted in our laboratory (Beckman Coulter (AU 5800 and AU 680) and Sysmex (XN 9000)). Hepatitis B serology was determined by commercial ELISA kits (Architect; Abbott Diagnostics Laboratories, Irving, Texas, USA)'. Serum HBV-DNA levels were measured using a COBAS TaqMan 48 (Roche Diagnostics, Germany).

\section{Statistical analysis}

Mean and standard deviation were used as descriptive statistics relating to continuous parameters. Student's $t$-test was used to determine intergroup differences. The $\chi^{2}$ test was used to assess the relationship between two categorical variables. Graphs were used for visual presentation of the differences between the groups. $P<0.05$ was considered statistically significant.

\section{Results}

In this study, we evaluated 197 patients (90 patients and 107 controls) (53.8\% female; mean age of patients, $48.5 \pm 12.4$ years; mean age of controls, $47.2 \pm 12.7$ years). The average HBV DNA lev- 
Table I. Laboratory and demographic data of inactive hepatitis B carriers (patients) and control subjects

\begin{tabular}{|c|c|c|c|}
\hline Parameter & Patients $(n=90)$ & Controls $(n=107)$ & $P$-value \\
\hline Female, $n(\%)$ & $43(47.8)$ & $63(58.9)$ & 0.120 \\
\hline Age [years] & $48.5 \pm 12.4$ & $47.2 \pm 12.7$ & 0.486 \\
\hline BMI $\left[\mathrm{kg} / \mathrm{m}^{2}\right]$ & $23.2 \pm 4.7$ & $24.2 \pm 5.1$ & 0.716 \\
\hline Smoking, $n(\%)$ & $33(36.7)$ & $40(37.4)$ & 0.917 \\
\hline $\mathrm{Hb}[\mathrm{g} / \mathrm{dl}]$ & $13.8 \pm 1.48$ & $14.1 \pm 4.81$ & 0.616 \\
\hline Creatinine $[\mathrm{mg} / \mathrm{dl}]$ & $0.80 \pm 0.14$ & $0.86 \pm 0.81$ & 0.475 \\
\hline $\mathrm{ALT}[\mathrm{U} / \mathrm{I}]$ & $23.1 \pm 10.1$ & $22.1 \pm 11.6$ & 0.565 \\
\hline GGT [U/I] & $24.7 \pm 15.8$ & $28.8 \pm 24.5$ & 0.174 \\
\hline Albumin [g/dl] & $4.33 \pm 0.36$ & $4.62 \pm 3.97$ & 0.482 \\
\hline Calcium [mg/dl] & $9.30 \pm 0.39$ & $10.16 \pm 0.84$ & 0.333 \\
\hline Total bilirubin [mg/dl] & $0.63 \pm 0.32$ & $0.66 \pm 0.35$ & 0.568 \\
\hline INR & $1.05 \pm 0.09$ & $1.04 \pm 0.06$ & 0.081 \\
\hline $\mathrm{TSH}[\mathrm{mU} / \mathrm{l}]$ & $3.65 \pm 1.89$ & $1.76 \pm 1.57$ & 0.305 \\
\hline HBV DNA $\left[\times 10^{3} \mathrm{IU} / \mathrm{ml}\right]$ & $6.83 \pm 12.67$ & - & - \\
\hline
\end{tabular}

el was $6.83 \pm 12.67 \times 10^{3} \mathrm{IU} / \mathrm{ml}$ (range: $15-51.990$ $\mathrm{IU} / \mathrm{ml})$. There was no difference between groups in terms of gender, smoking, and body mass index (BMI) $(p>0.05)$. Hemoglobin, alanine transaminase (ALT), $\gamma$-glutamyl transpeptidase (GGT), creatinine, albumin, calcium, total bilirubin, and INR were similar in both groups $(p>0.05)$ (Table I).

The incidence of HP was significantly higher in the inactive hepatitis B carrier group than the control group ( $75.6 \%$ vs. $53.3 \%$, respectively) ( $p=$ 0.001). There were no intergroup differences with respect to incidence of inflammation, activity, atrophy, and intestinal metaplasia $(p>0.05)$ (Figure 1).

HP positivity was evaluated separately in the antrum and corpus and showed significant differences between the two groups (Table II). In the antrum, but not in the corpus, differences were found with respect to severity of HP (Table II). No intergroup differences were found in either the antrum or the corpus with regard to inflammation, activity, atrophy, and intestinal metaplasia severity $(p>0.05)$ (Figures 2 and 3 ).

While $12.2 \%$ of endoscopically inactive hepatitis B carriers had gastric or duodenal ulcers, this rate was $6.5 \%$ in the control group ( $p=0.360)$ (Table III).

When comparing the HP positive (+) versus negative (-) group in the patient group, the HP (+) group was younger ( $46.2 \pm 11$ vs. $55.8 \pm 12.1$ years, respectively, $p=0.001)$. Although HBV DNA levels were higher in the HP (+) group, this was not statistically significant $(2.63 \pm 4.63$ vs. $8.19 \pm 14.10 \times$

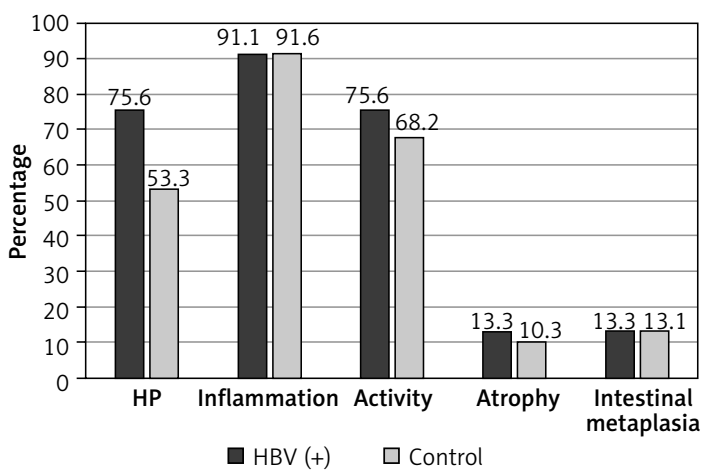

Figure 1. Histopathological evaluation of patients and controls. Only HP frequency showed a significant difference ( $p=0.001$ for HP, $p>0.05$ for others)

$\left.10^{3} \mathrm{IU} / \mathrm{ml}\right)(p=0.073)$. Further, inflammation and activity were higher in the HP (+) group, but there was no difference in other histopathological and endoscopic evaluation parameters (Table IV).

We further divided the groups according to the level of HBV DNA. HP was high in the group with HBV DNA $\geq 2,000 \mathrm{IU} / \mathrm{ml}$, but this was not statistically significant ( $85.0 \%$ vs. $68 \%$, respectively) $(p=0.062)$. Inflammation was significantly higher in the HBV DNA $\geq 2,000 \mathrm{IU} / \mathrm{ml}$ group, but there was no difference in other histopathological and endoscopic evaluations (Table V).

\section{Discussion}

Helicobacter pylori infection is endemic in the world and is considered to be a group 1 carcinogen 
Table II. HP frequency and grade in inactive hepatitis B carriers (patients) and controls

\begin{tabular}{|lccc|}
\hline Parameter & Patients $(n=90)$ & Controls $(n=107)$ & $P$-value \\
\hline HP (-) (antrum (-) and corpus (-), $n(\%)$ & $22(24.4)$ & $50(46.7)$ & 0.001 \\
\hline HP (+) (antrum (+) or corpus (+), $n(\%)$ & $68(75.6)$ & $57(53.3)$ & 0.001 \\
\hline Antrum HP (+) (+ or ++ or +++), $n(\%)$ & $64(71.1)$ & $54(50.5)$ & 0.001 \\
\hline Corpus HP (+) (+ or ++ or +++), $n(\%)$ & $47(52.2)$ & $44(41.1)$ & 0.015 \\
\hline Antrum HP (-), $n(\%)$ & $26(28.9)$ & $53(49.5)$ & 0.012 \\
\hline Antrum HP (+), $n(\%)$ & $25(27.8)$ & $15(14.0)$ & 0.027 \\
\hline Antrum HP (++), $n(\%)$ & $32(35.6)$ & $29(27.1)$ & 0.043 \\
\hline Antrum HP (+++), $n(\%)$ & $7(7.8)$ & $10(9.3)$ & 0.856 \\
\hline Corpus HP (-), $n(\%)$ & $43(47.8)$ & $63(58.9)$ & 0.079 \\
\hline Corpus HP (+), $n(\%)$ & $21(23.3)$ & $12(11.2)$ & 0.048 \\
\hline Corpus HP (++), $n(\%)$ & $25(27.8)$ & $28(26.2)$ & 0.275 \\
\hline Corpus HP (+++), $n(\%)$ & $1(1.1)$ & $4(3.7)$ & \\
\hline
\end{tabular}

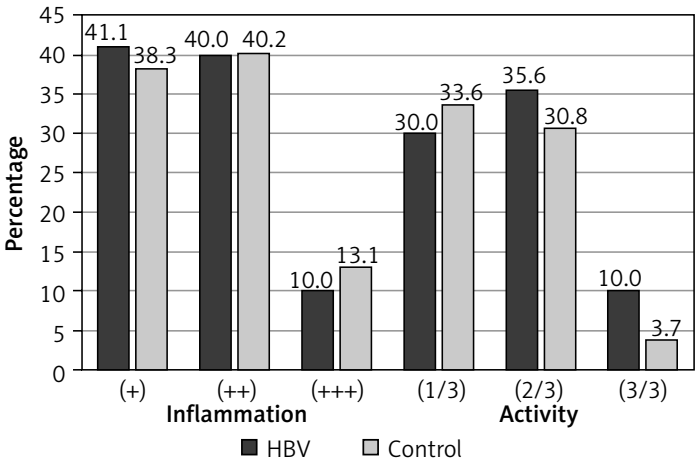

Figure 2. In terms of inflammation and activity, there is no difference between the patient and control groups $(p>0.05)$

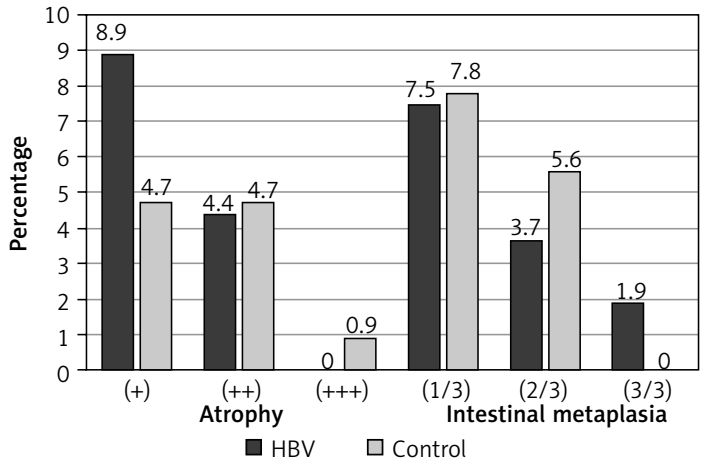

Figure 3. In terms of atrophy and intestinal metaplasia, there is no difference between inactive hepatitis B carriers and control group ( $p>0.05$ )

Table III. Endoscopic findings of patients and controls

\begin{tabular}{|lccc|}
\hline Parameter & Patients $(n=90)$ & Controls $(n=107)$ & $P$-value \\
\hline Peptic ulcer, $n(\%)$ & $11(12.2)$ & $7(6.5)$ & 0.360 \\
\hline Gastritis or duodenitis, $n(\%)$ & $78(86.7)$ & $98(91.6)$ & 0.593 \\
\hline Esophagitis, $n(\%)$ & $1(1.1)$ & $2(1.9)$ & 0.654 \\
\hline
\end{tabular}

for gastric cancer [17]. The relationship between HP and liver diseases has been investigated in previous studies and it has been found that the incidence of HP in HBV-related cirrhosis and HCC patients is higher than in healthy volunteers $[12,18,19]$. Helicobacter pylori infection can be diagnosed by various invasive and noninvasive methods. Endoscopic biopsy is one of the gold standard methods. The disadvantage of this method is the heterogeneous distribution of HP in the stomach [12]. Therefore, we addressed this limitation by taking at least two samples from the antrum and corpus.
In our study, we found the HP rate in inactive HBV patients to be significantly higher than the control group $(75.6 \%$ vs. $53.3 \%$ respectively, $p=$ 0.001 ). Huang and Cui, in their $13-C$ urea breath study in patients with chronic hepatitis, found that the HP rate was significantly higher than in healthy volunteers ( $58 \%$ vs. $23.3 \%$, respectively; $p<0.05)$ [12]. In the same study, HP was found to be $79.3 \%$ for patients with HBV-related cirrhosis and $68.9 \%$ for those with HBV-associated hepatic carcinoma. Fan et al. in their serological study compared patients with hepatitis B and 
Table IV. Comparison of HP (+) group with HP (-) group in HBV patients

\begin{tabular}{|c|c|c|c|}
\hline Parameter & $\mathrm{HP}(-)(n=22)$ & $\mathrm{HP}(+)(n=68)$ & $P$-value \\
\hline Female, $n(\%)$ & $9(40.9)$ & $34(50.0)$ & 0.458 \\
\hline Age [years] & $55.8 \pm 12.1$ & $46.2 \pm 11.0$ & 0.001 \\
\hline Smoking, $n(\%)$ & $8(36.4)$ & $25(36.8)$ & 0.973 \\
\hline HBV DNA $\left[\times 10^{3} \mathrm{IU} / \mathrm{ml}\right]$ & $2.63 \pm 4.63$ & $8.19 \pm 14.10$ & 0.073 \\
\hline $\operatorname{AFP}[\mu \mathrm{g} / \mathrm{I}]$ & $3.43 \pm 2.19$ & $3.67 \pm 2.66$ & 0.706 \\
\hline $\mathrm{Hb}[\mathrm{g} / \mathrm{dl}]$ & $14.1 \pm 1.55$ & $13.7 \pm 1.45$ & 0.289 \\
\hline ALT $[U / I]$ & $19.5 \pm 8.8$ & $24.2 \pm 11.4$ & 0.076 \\
\hline Inflammation (+), $n(\%)$ & $15(68.2)$ & $67(98.5)$ & $<0.001$ \\
\hline Activity (+), $n(\%)$ & $4(18.2)$ & $64(94.1)$ & $<0.001$ \\
\hline Atrophy $(+), n(\%)$ & $3(13.6)$ & $9(13.2)$ & 0.999 \\
\hline Int. Met. (+), n (\%) & $3(13.6)$ & $9(13.2)$ & 0.593 \\
\hline Peptic ulcer, $n(\%)$ & $0(0.0)$ & $11(16.2)$ & 0.032 \\
\hline Gastritis or duodenitis, $n$ (\%) & $21(95.5)$ & $57(83.8)$ & 0.174 \\
\hline Esophagitis, $n$ (\%) & $1(4.5)$ & $0(0.0)$ & - \\
\hline
\end{tabular}

$A F P$ - $\alpha$-fetoprotein, $H b$ - hemoglobin, ALT - alanine transaminase, Int. Met - intestinal metaplasia.

Table V. Assessment according to HBV DNA level (HBV DNA $<2000 \mathrm{IU} / \mathrm{ml}$ and HBV DNA $\geq 2000 \mathrm{IU} / \mathrm{ml}$ )

\begin{tabular}{|c|c|c|c|}
\hline Parameter & $\begin{array}{c}\text { HBV DNA }<2,000 \\
(n=50)\end{array}$ & $\begin{array}{l}\text { HBV DNA } \geq 2,000 \\
(n=40)\end{array}$ & $P$-value \\
\hline Female, $n(\%)$ & $25(50.0)$ & $18(45.0)$ & 0.637 \\
\hline Age [years] & $48.9 \pm 12.8$ & $48.1 \pm 12.1$ & 0.760 \\
\hline Smoking, $n(\%)$ & $22(44.0)$ & $11(27.5)$ & 0.107 \\
\hline HBV DNA $\left[\times 10^{3} \mathrm{IU} / \mathrm{ml}\right]$ & $0.58 \pm 0.56$ & $14.65 \pm 15.91$ & 0.000 \\
\hline $\operatorname{AFP}[\mu \mathrm{g} / \mathrm{I}]$ & $3.26 \pm 1.75$ & $4.04 \pm 3.25$ & 0.147 \\
\hline $\mathrm{Hb}[\mathrm{g} / \mathrm{dl}]$ & $13.9 \pm 1.59$ & $13.8 \pm 1.34$ & 0.854 \\
\hline $\operatorname{ALT}[\mathrm{U} / \mathrm{l}]$ & $22.5 \pm 11.9$ & $23.7 \pm 9.8$ & 0.621 \\
\hline $\mathrm{HP}(+), n(\%)$ & $34(68.0)$ & $34(85.0)$ & 0.062 \\
\hline Inflammation (+), $n(\%)$ & $44(88)$ & $38(95)$ & 0.013 \\
\hline Activity (+), $n(\%)$ & $34(68)$ & $34(85)$ & 0.917 \\
\hline Atrophy (+), $n(\%)$ & $6(12)$ & $6(15)$ & 0.762 \\
\hline Int. Met. (+), $n(\%)$ & $5(10)$ & $7(17.5)$ & 0.579 \\
\hline Peptic ulcer, $n(\%)$ & $6(12.0)$ & $5(12.5)$ & 0.667 \\
\hline Gastritis or duodenitis, $n$ (\%) & $43(86.0)$ & $35(87.5)$ & 0.931 \\
\hline Esophagitis, $n$ (\%) & $1(2.0)$ & $0(0.0)$ & - \\
\hline
\end{tabular}

AFP - $\alpha$-fetoprotein, $\mathrm{Hb}$ - hemoglobin, ALT - alanine transaminase, HP - Helicobacter pylori, Int. Met. - intestinal metaplasia.

healthy controls and found that the former group had a high HP $(57.3 \%$ vs. $42.3 \%$, respectively, $p<0.05)$ [14]. In another study, the incidence of $\mathrm{HP}$ in asymptomatic HBV carriers was similar to the control group $(38.67 \%$ vs. $35.49 \%$, respectively, $p>0.05)$ [20]. In a meta-analysis conducted in 2016, the rate of HP was 2.44 times in chronic hepatitis $B$ (odds ratio), 4.28-times in HBV-associated cirrhosis, and 6.02-fold higher in HBV-associated HCC as compared to the healthy population 
[11]. In a study by Ponzetto et al., the HP-antibody ratio was significantly higher in patients with HBV-related cirrhosis than healthy controls $(89 \%$ vs. $59 \%$, respectively, $p<0.05$ ) [13]. In addition, in a meta-analysis evaluating the relationship between HP and HCV, the rate of HP in HCV patients was 2.93-fold higher than in the control group. In this meta-analysis, HP was found to be high in patients with cirrhosis and HCC due to HCV (odds ratios: 4.48 and 5.45, respectively) [10]. In another study, HP-infected HCV patients were found to have more advanced fibrosis than HCV patients without HP infection [21]. These findings suggest that HP adversely affects the course of hepatotropic viruses. In another study, the HP rate was higher in cirrhosis due to HBV than in cirrhosis due to alcoholism ( $67.7 \%$ vs. $28.6 \%$, respectively) [22]. This suggests that HBV increases the incidence of HP by showing different immunopathology.

The rate of HP in inactive hepatitis $B$ patients was higher than in the control group in our study, but we found no difference in the incidence of atrophy, intestinal metaplasia, activity, inflammation, or peptic ulcers. To our best knowledge, there is no study yet that has evaluated histopathology in patients who are inactive hepatitis B carriers. In a previous study, the ratio of chronic gastritis and glandular metaplasia had been found in cirrhotic patients as follows: $15.6 \%$ of patients of Child-Pugh A, $70 \%$ of Child-Pugh B, and $100 \%$ of Child-Pugh C [23]. In a Turkish study on patients with dyspepsia, atrophy was found in only $5.5 \%$ of cases [24]. In our study, the incidence of atrophy and intestinal metaplasia was approximately $13 \%$. This issue wherein only the HP rate is high in patients with inactive hepatitis $B$, but not other factors such as inflammation, atrophy, and intestinal metaplasia, when compared to the control group, warrants further investigation and discussion.

In our study, the HP rate was higher in the group with HBV DNA $\geq 2,000 \mathrm{IU} / \mathrm{ml}$ than the group with HBV DNA $<2,000 \mathrm{IU} / \mathrm{ml}$, but this was not statistically significant ( $85.0 \%$ vs. $68 \%$, respectively) ( $p=$ 0.062). In Huang's ${ }^{3} \mathrm{C}$-urea breath test study, HPV was significantly higher in the HBV-DNA $\geq 10^{3}$ copies $/ \mathrm{ml}$ group than the HBV-DNA $<10^{3}$ copies $/ \mathrm{ml}$ group [12]. In some studies, no relation was found between HBV DNA levels and HP rate $[25,26]$.

In conclusion, in this study, we investigated the frequency of HP in inactive hepatitis B carriers, and the rate of HP was higher than in the control group. Inflammation, activity, atrophy, intestinal metaplasia, and ulcer frequency were not different though. While only HP prevalence was investigated in previous studies with inactive hepatitis $B$ patients, no histopathological evaluation was performed. Large-scale studies are needed for validation.

\section{Conflict of interest}

The authors declare no conflict of interest.

\section{References}

1. Suerbaum S, Michetti P: Helicobacter pylori infection. N Engl J Med 2002; 347: 1175-86.

2. Mitchell H, Katelaris P. Epidemiology, clinical impacts and current clinical management of Helicobacter pylori infection. Med J Aust 2016; 10: 376-80.

3. Waluga M, Kukla M, Żorniak M, Bacik A, Kotulski R. From the stomach to other organs: Helicobacter pylori and the liver. World J Hepatol 2015; 18: 2136-46.

4. Tan HJ, Goh KL. Extragastrointestinal manifestations of Helicobacter pylori infection: facts or myth? A critical review. J Digest Dis 2012; 13: 342-9.

5. Goo MJ, Ki MR, Lee HR, et al. Helicobacter pylori promotes hepatic fibrosis in the animal model. Lab Invest 2009; 89: 1291-303.

6. Stalke P, Al-Soud WA, Bielawski KP, et al. Detection of Helicobacter species in liver and stomach tissues of patients with chronic liver diseases using polymerase chain reaction-denaturing gradient gel electrophoresis and immunohistochemistry. Scand J Gastroenterol 2005; 40: 1032-41.

7. Cirak MY, Akyon Y, Megraud F. Diagnosis of Helicobacter pylori. Helicobacter 2007; 12: 4-9.

8. Schweitzer A, Horn J, Mikolajczyk RT, Krause G, Ott JJ. Estimations of worldwide prevalence of chronic hepatitis $B$ virus infection: a systematic review of data published between 1965 and 2013. Lancet 2015; 386: 1546-55.

9. Bonino F, Brunetto MR. Chronic hepatitis B e antigen ( $\mathrm{HBeAg})$ negative, anti-HBe positive hepatitis B: an overview. J. Hepatol 2003; 39: 160-3.

10. Wang J, Li WT, Zheng YX, et al. The Association between Helicobacter pylori infection and chronic hepatitis C: a meta-analysis and trial sequential analysis. Gastroenterol Res Pract 2016; 2016: 8780695.

11. Wang J, Chen RC, Zheng YX, et al. Helicobacter pylori infection may increase the risk of progression of chronic hepatitis B disease among the Chinese population: a meta-analysis. Int J Infect Dis 2016; 50: 30-7.

12. Huang J, Cui J. Evaluation of Helicobacter pylori infection in patients with chronic hepatic disease. Chin Med J 2017; 130: 149-54.

13. Ponzetto A, Pellicano R, Leone N, Berrutti M, Turrini F, Rizzetto M. Helicobacter pylori seroprevalence in cirrhotic patients with hepatitis B virus infection. Neth J Med 2000; 56: 206-10.

14. Fan XG, Zou YY, Wu AH, Li TG, Hu GL, Zhang Z. Seroprevalence of Helicobacter pylori infection in patients with hepatitis B. Br J Biomed Sci 1998; 55: 176-8.

15. Abid SG, Aboud RS, Abudl-Razak SA, Aboud AS. Evaluation of anti-Helicobacter pylori antibodies level in sera of patients with chronic hepatitis B. World J Exp Biosci 2015; 3: 18-21.

16. Dixon MF, Genta RM, Yardley JH, Correa P. Classification and grading of gastritis. The updated Sydney System. International Workshop on the Histopathology of Gastritis, Houston 1994. Am J Surg Pathol 1996; 20 : 1161-81.

17. IARC Working Group on the Evaluation of Carcinogenic Risks to Humans. IARC Monographs on the Evaluation of Carcinogenic Risks to Humans. Vol. 61. Lyon, France IARC 1994: 1-241. 
18. Okushin K, Tsutsumi T, ikeuchi K, et al. Helicobacter pylori infection and liver diseases: epidemiology and insights into pathogenesis. World I Gastroenterol 2018; 24: 3617-25.

19. Segura-López FK, Güitrón-Cantú A, Torres J. Association between Helicobacter spp. infections and hepatobiliary malignancies: a review. World J Gastroenterol 2015; 21: 1414-23.

20. Wang MY, Yue JY, Zhang YX, Liu XD, Gao XZ. Helicobacter pylori infection in asymptomatic HBV carriers, alcohol users and normal adult population in Shandong Province, China. Clin Res Hepatol Gastroenterol 2011; 35: 560-2.

21. Sakr SA, Badrah GA, Sheir RA. Histological and histochemical alterations in liver of chronic hepatitis $\mathrm{C}$ patients with Helicobacter pylori infection. Biomed Pharmacother 2013; 67: 367-74.

22. Pogorzelska J, Łapińska M, Kalinowska A, Łapiński TW, Flisiak R. Helicobacter pylori infection among patients with liver cirrhosis. Eur J Gastroenterol Hepatol 2017; 29: 1161-5.

23. Mohamed AA, Elshimy AA, El Sadik AO, et al. Association between severity of liver disease, frequency of Helicobacter pylori infection, and degree of gastric lesion in Egyptian patients with hepatitis B virus infection. Am J Trop Med Hyg 2018; 98: 221-6.

24. Türkay C, Erbayrak M, Bavbek N, Yenıdünya S, Eraslan E, Kasapoğlu B. Helicobacter pylori and histopathological findings in patients with dyspepsia. Turk J Gastroenterol 2011; 22: 122-7.

25. Ji SW, Wang JB, Zhang YG. The Helicobacter pylori infection in patients with chronic hepatitis $B$ and the relative factor analysis. Liver 2008; 1: 205-7.

26. Wang GS, Li C, Chen FJ, Xiang XX. The study of Helicobacter pylori infection in patients with HBV related liver disease. J Clin Med Pract 2013; 17: 39-41. 